\title{
Does mosquito mortality in WHO insecticide susceptibility tests relate to mosquito mortality in LLIN experimental hut studies?
}

\author{
Olivier JT Briët ${ }^{1,2^{*}}$, Nakul Chitnis ${ }^{1,2}$, Melissa Penny ${ }^{1,2}$ \\ From Challenges in malaria research \\ Basel, Switzerland. 10-12 October 2012
}

\begin{abstract}
Background
With the rise of insecticide resistance, there are concerns that insecticide treated nets (LLINs) will become less effective against malaria transmission. The WHO insecticide susceptibility (tube/ cylinder) test is a standard for estimating mosquito susceptibility to insecticide. The test measures the proportion of mosquitoes that die when exposed to an insecticide with a certain concentration. Whereas, with fully susceptible mosquito populations, mortality is $100 \%$ with $0.05 \%$ deltamethrin, but with resistant populations, mortality can be below $15 \%$. However, little is known how susceptibility results in these tests relate to effectiveness of LLINs in the field. Experimental huts provide semi-field conditions and provide a more direct way of estimating the effect of susceptibility of mosquitoes to interventions than WHO susceptibility tests. This work assesses the degree to which mortality in WHO susceptibility tests correlates to mortality in experimental hut studies with LLINs.
\end{abstract}

\section{Materials and methods}

For seven wild mosquito populations, published experimental hut results [1-5] were available for untreated, twenty times washed, and unwashed nets, for which the insecticide content was also measured. Nets were either artificially holed (hut assays for six populations), or intact (hut essays for one population). For six of these populations, mortality in WHO susceptibility tests were also published. These data were used to estimate deterrence (reduction in hut entry), the proportion of mosquitoes attacking of those entered, and pre- and post prandial mortality, as a function of LLIN insecticide concentration

'Department of Epidemiology and Public Health, Swiss Tropical and Public Health Institute, Basel, Switzerland

Full list of author information is available at the end of the article and as a function of holed area. These variables were also used to define personal protection (reduction in bites received), and corrected mortality (mosquito mortality), as a function of insecticide concentration and holed area. Using these parameterizations, the corrected mortality in experimental huts for all populations was calculated for a standard net with a fixed deltamethrin concentration of $17.44 \mathrm{mg} \cdot \mathrm{m}^{-2}$ and $96 \mathrm{~cm}^{2}$ holed area.

\section{Results}

The Pearson correlation coefficient for the correlation between corrected mortality values and mortality in WHO susceptibility tests was strong and positive at $\mathrm{r}=0.92$. However, for personal protection, the correlation was much weaker $(r=0.54)$.

\section{Conclusions}

Our analysis concludes that the WHO susceptibility tests give a good indication of the killing efficacy of LLINs in semi-field conditions. However, the efficacy of LLINs in the field is not only determined by direct mortality, but also by personal protection and deterrence, for which correlations are much weaker.

\footnotetext{
Author details

${ }^{1}$ Department of Epidemiology and Public Health, Swiss Tropical and Public Health Institute, Basel, Switzerland. 'University of Basel, Basel, Switzerland.

Published: 15 October 2012
References
1. Tungu P, Magesa S, Maxwell C, Malima R, Masue D, Sudi W, Myamba J, Pigeon O, Rowland M: Evaluation of PermaNet 3.0 a deltamethrin-PBO combination net against Anopheles gambiae and pyrethroid resistant Culex quinquefasciatus mosquitoes: an experimental hut trial in Tanzania. Malar J 2010, 9:21, 21


2. Corbel V, Chabi J, Dabire RK, Etang J, Nwane R, Pigeon O, Akogbeto M, Hougard JM: Field efficacy of a new mosaic long-lasting mosquito net (PermaNet 3.0) against pyrethroid-resistant malaria vectors: a multi centre study in Western and Central Africa. Malar J 2010, 9:113, 113.

3. Koudou BG, Koffi AA, Malone D, Hemingway J: Efficacy of PermaNet(R) 2.0 and PermaNet(R) 3.0 against insecticide-resistant Anopheles gambiae in experimental huts in Cote d'lvoire. Malar J 2011, 10:172, 172.

4. N'Guessan R, Asidi A, Boko P, Odjo A, Akogbeto M, Pigeon O, Rowland M: An experimental hut evaluation of PermaNet((R)) 3.0, a deltamethrinpiperonyl butoxide combination net, against pyrethroid-resistant Anopheles gambiae and Culex quinquefasciatus mosquitoes in southern Benin. Trans R Soc Trop Med Hyg 2010, 104(12):758-765.

5. Van Bortel W, Chinh VD, Berkvens D, Speybroeck N, Trung HD,

Coosemans M: Impact of insecticide-treated nets on wild pyrethroid resistant Anopheles epiroticus population from southern Vietnam tested in experimental huts. Malar J 2009, 8:248, 248.

doi:10.1186/1475-2875-11-S1-043

Cite this article as: Briët et al.: Does mosquito mortality in WHO

insecticide susceptibility tests relate to mosquito mortality in LLIN experimental hut studies? Malaria Journal 2012 11(Suppl 1):O43.

\section{Submit your next manuscript to BioMed Central} and take full advantage of:

- Convenient online submission

- Thorough peer review

- No space constraints or color figure charges

- Immediate publication on acceptance

- Inclusion in PubMed, CAS, Scopus and Google Scholar

- Research which is freely available for redistribution

Submit your manuscript at www.biomedcentral.com/submit
Ciomed Central 